\title{
Erratum to: Cherry-Picking Records in Independent Medical Examinations: Strategies for Intervention to Mitigate a Legal and Ethical Imbroglio
}

\author{
Michael E. Schatman • Janet L. Thoman
}

Published online: 13 August 2014

(C) Springer Science+Business Media New York 2014

\section{Erratum to: Psychol. Inj. and Law (2014) 7:191-196 DOI 10.1007/s12207-014-9194-y}

This article was originally published with errors that were introduced during the editing process. The corrected version of this article appears below.

\begin{abstract}
Independent medical examinations (IMEs) theoretically construe a means of "independently" assessing a claimant's physical and psychological status, as well as to determine whether treatment that has been and will potentially be provided is reasonable and necessary. IMEs may be undertaken both for the plaintiff and defense or related adversaries. In the present case, we focus on IMEs that are requested by insurers. One can query the degree to which IMEs are actually "independent." It has been posited that one of the ways in which claims managers contribute to potential bias against claimants is through a process of selectively providing examiners with medical records, which has been described as "cherry-picking." Despite the existence of rules and laws that are designed to prevent cherry-picking, the practice still occurs. This analysis discusses the legal as well as ethical implications of cherry-picking and its potential to cause or exacerbate psychological injury that a claimant may experience. The authors propose that psychologists as well as attorneys can advocate for their vulnerable patients/clients in cases of cherry-picking. A recent case study
\end{abstract}

The online version of the original article can be found at http://dx.doi.org/ 10.1007/s12207-014-9194-y.

M. E. Schatman $(\bowtie)$

Foundation for Ethics in Pain Care, 1601 114th Ave. SE, Suite 100, Bellevue, WA 98004, USA

e-mail: headdock@comcast.net

J. L. Thoman

Law Office of Janet L. Thoman, Issaquah, WA, USA from the clinical practice of the first author in which he so acted is provided. We conclude with a discussion of the ethical implications of the psychologist's intervention.

Keywords Independent medical examination (IME) . Cherry-picking $\cdot$ Bad faith $\cdot$ Ethics $\cdot$ Advocacy

\section{Introduction}

Personal injury insurers require a means to assess the physical and psychological status of their insured, as occurrences of unconscious symptom exaggeration (Dersh, Polatin, Leeman and Gatchel, 2004; Howard, Kishino, Johnston, Worzer and Gatchel, 2010), frank malingering (Greve, Ord, Bianchini and Curtis, 2007; Ochoa and Verdugo, 2010), and over-provision of services (Eisendrath, Rand and Feldman, 1996; Green 2011) exist in personal injury cases. Without independent medical examinations (IMEs), insurers' costs would escalate to a level that would potentially make the provision of coverage unrealistic. However, a substantial body of literature exists questioning the ethical foundation of independent medical examinations (IMEs) in medicolegal cases (Benner, 2007; Gaughwin, 2004; Kulich and Baker, 1997; Ky, Hameed and Christo, 2009; Schatman, 2011, 2012; Sullivan and Loeser, 1992).

Lax, Manetti, and Klein (2004) have noted that the use of the term "independent" to describe IMEs suggests that these examinations are unbiased, particularly in comparison to the opinions of the treating physicians. However, results of their study of a workers compensation population determined that this assumption was unfounded. Schofferman (2007) has noted that IME physicians are prone to biases, in that they are financially motivated to maintain a positive relationship with the insurance carriers that hire them. Although these physicians are expected to be held to the same scientific and ethical standards as are treating physicians, their primary obligation is 
not to the patient. Baer (2005), former Vice Chair of the American College of Forensic Examiners Institute, noted, "I believe that even the fairest of us experiences unconscious pressure to report the results of these examinations in favor of our employer. The reason is undeniable: we want to be hired again" (p. 33). Whether the bias is unconscious or conscious is perhaps immaterial; the bottom line is that it potentially exists, if not in all cases, then at least in many.

The IME physician's or psychologist's review of the relevant medical records is as important as the actual examination of the patient in the IME. Appleby and Tarver (2006) refer to records as the "primary source of information in litigation involving personal injury." It has been noted, for example, that in neuropsychological IMEs, the record review is of extreme importance due a lack of reliability - whether it is conscious or unconscious - of examinee self-report (Bush and Heilbronner, 2012). Which records should the examining physician or psychologist review prior to conducting the in vivo assessment of the patient? Probably all of them. In a chapter on impairment and disability evaluations, Martelli, Zasler, and Grayon (1999) wrote, "It would seem logical that lawyers who retain experts should provide all pertinent records to the expert without preferentially 'picking and choosing' which records are 'relevant.' Such a practice can certainly inject a bias, whether actual or perceived. The practice of knowingly withholding data that could be damaging to their client from the expert witness clearly violates ethical standards of medical and health professionals" (p. 235). Similarly, withholding data by plaintiffs' attorneys, should it occur, would also be ethically questionable.

\section{Current Rules}

Not surprisingly, rules on which records should be reviewed vary to some degree between jurisdictions. However, recommendations for inclusion of all relevant medical records seem to dominate. For example, the Oregon IME guidelines (Oregon Department of Consumer and Business Services, 2011) state that the examiner should "Review the medical records provided to (him or her), including any testing and studies," and "If you do not receive all the medical records or diagnostic studies, contact the insurer" (p. 5). Other states' rules are more detailed, yet stress inclusion. For example, Colorado's rules (Colorado Department of Labor and Employment, 2013) stipulate, "Form/Content of Medical Records Package: Pertinent medical records shall include all (italics added for emphasis by authors) medical reports and medical records reflecting the diagnosis and treatment of the claimant's work-related injury and shall include available medical records regarding relevant pre-existing condition(s) or work-related injury(ies)" (rule 11-3). The rules further stipulate that records failing to meet these requirements require resubmission to the IME physician and all other parties in the correct format in a timely manner. Finally, they indicate that failure to properly resubmit such records in a timely fashion may result in cancelation of the IME by the director at the cost of the submitting party. Interestingly, some states place the responsibility to ensure that IME providers receive all relevant records on the claimant and/or the claimant's attorney. According to the Maryland rule (Maryland Workers' Compensation, 2013), "Before obtaining an appointment for an independent medical exam, it will be necessary for the claimant or the claimant's attorney to request all relevant medical records from every physician or hospital that treated the claimant for the work-related accident." The Maryland rule is in stark contrast to the rule in New Brunswick, Canada, which was developed by a joint panel of attorneys and physicians (Law Society of New Brunswick et al., 2002), which places the responsibility for obtaining all records on the defendant: "To assist the physician performing the independent medical examination, the lawyer representing the defendant must provide the physician performing the independent medical examination, referred to as the examining medical practitioner, with a copy of every report made by every medical practitioner who has treated the party to be examined in respect to the mental or physical condition in issue, at least 2 days before the day appointed for the examination" (p. 16).

\section{Legal and Ethical Concerns}

The American Medical Association (AMA) (American Medical Association, 2005) has addressed ethical issues associated with "cherry-picking" records provided to an IME examiner in a 2005 document, writing "Intellectual honesty when editing records is essential. History should be recounted objectively without attempt to color or bias the history. Selective editing that unfairly slants the history negates the value of the report" and "Past medical history record review (prior to the subject incident) should be listed in a different subsection than the record review for the current injury. All clinical encounters, diagnostic tests, and outcomes relevant to the current condition should be listed" (p. 11). This AMA document is important, for it stipulates that even past medical history "prior to the subject incident" should be provided to the examiner(s), given that these records may potentially have some bearing on the claimant's current injury and his/her recovery from it.

One can query, when rules and guidelines universally stipulate that all relevant records (i.e., those likely to have an impact on the examiner's findings and rendered opinions) are provided to an examiner prior to conducting an IME, why does the practice of "cherry-picking" continue at all? Both authors of this paper - a psychologist/patient advocate and a plaintiff's attorney - continue to witness such behavior on a regular basis in their professional practices. A case example of 
such will be provided later in this analysis. One explanation for this inappropriate behavior is that it is typically not claimants, defendants, or attorneys who engage in "cherry-picking" of records that are provided to IME doctors but rather select claims managers - who might have a strong motivation to do so.

In an article in the Connecticut Insurance Law Journal (Stempel, 2009), the author noted that claims managers are typically poorly compensated individuals whose duties are not particularly glamorous-describing them as "low-budget drudgery." As they are immune from judicial regulation, their incentive to perform their duties competently is minimal, resulting in a tendency to "frequently act negligently, recklessly, or even in bad faith, needlessly creating claims imbroglios that could be avoided, minimized, or streamlined" (p. 603). Accordingly, the author posited that claims managers shall be held accountable," at least in tort for misconduct even if not for bad faith in the manner of an insurer" (p. 603). We certainly echo this position, as experience tells us that plaintiffs in medicolegal cases could be injured both psychologically and physically by such behavior (Schatman and Sullivan, 2010). Nevertheless, we also note that Stempel (2009) has posited that actual cases are so few that aggrieved policyholders or claimants may never have considered legal action. In addition, though, cases might be quickly dismissed, and the claims manager may never be challenged in any way for such behavior.

"Bad faith" is an amorphous legal concept susceptible to subjective colorization by both plaintiff and defense counsel. In the insurance context, it is most simply defined as an insurer's "unreasonable and unfounded (though not necessarily fraudulent) refusal to provide coverage in violation of the duties of good faith and fair dealing." Good faith is defined as, "a state of mind consisting in (1) honesty and belief or purpose, (2) faithfulness to one's duty or obligation, (3) observance of reasonable commercial standards of fair dealing in a given trade or business, and (4) absence of intent to defraud or to seek unconscionable advantage" (Black and Nolan, 1999) (p. 701). There is no benchmark objective evidence that can perfectly elucidate a person's intent, let alone reveal unequivocally the intent of a large corporation. Bad faith is demonstrated through a pattern of conduct by the company's representatives.

"There is an implied covenant of good faith and fair dealing in every contract that neither party will do anything which will injure the right of the other to receive the benefits of the agreement" (Brown v. Superior Court, 1949) (p. 564). This principle is applicable to policies of insurance (Hilker v. Western Automobile Ins. Co, 1930). In the Hilker case, it is pointed out that the rights of the insured "go deeper than the mere surface of the contract written for him by defendant" and that implied obligations are imposed "based upon those principles of fair dealing which enter into every contract." (Comunale v. Traders and General Ins. Co, 1958) (p. 258). Similarly, “... (I)n every insurance contract, there is an implied covenant of good faith and fair dealing. The duty to so act is immanent in the contract whether the company is attending to the claims of third persons against the insured or the claims of the insured itself. Accordingly, when the insurer unreasonably and in bad faith withholds payment of the claim of its insured, it is subject to liability in tort" (Gruenberg v. Aetna Ins. Co, 1973) (p. 575).

Bad faith law is a hybrid of tort, contract, and agency. While a compelling argument can be made for a cause of action directly against individual claims managers (Stempel, 2009), the law has not yet evolved to the point of allowing this means of redress. Contract law requires privity of contract for a claimant to have standing to sue. The contract is with the insurance company, not with individual claims managers or adjustment companies. In tort, the argument can be made that the claims manager owes a duty to the insured, and by breaching that duty causes harm. However, the limited benefit available to the plaintiff for bad faith is generally too prohibitively expensive and time consuming to justify mounting an attack to create new law in this area.

Requiring accountability by claims managers would achieve one of the ends of the civil justice system: to discourage unfair behavior that is harmful to others. However, law in the area of insurance contracts does provide a deterrent effect by placing accountability on the insurer which, in turn, is responsible for the actions of the claims managers under agency law principles. Currently, an aggrieved claimant can sue the insurer for the actions of the claims handler for bad faith. Actions such as cherry-picking records do show the intent of the insurer, although this alone is insufficient to prove a pattern of conduct rising to the level of actionable bad faith.

Fortunately, there are means short of expensive and timeconsuming litigation available to address this conduct. The National Association of Insurance Commissioners publishes model regulations for claims handling. Often found in states' insurance regulations under the title "Unfair Claims Settlement Practices," the model regulation provides, in pertinent part:

\section{Section 4. Unfair Claims Practices Defined}

Any of the following acts by an insurer, if committed in violation of Section 3, constitutes an unfair claims practice: ...

... C. Failing to adopt and implement reasonable standards for the prompt investigation and settlement of claims arising under its policies; D. Not attempting in good faith to effectuate prompt, fair and equitable settlement of claims submitted in which liability has become reasonably clear;

E. Compelling insureds or beneficiaries to institute suits to recover amounts due under its policies by offering substantially less than the amounts ultimately recovered in suits brought by them; 
F. Refusing to pay claims without conducting a reasonable investigation. (National Association of Insurance Commissioners, 1997) (p. 900-2).

The provisions above require the insurer to act in good faith and conduct reasonable and fair investigations. It requires minimal effort to demonstrate that excluding pertinent records violates the provisions and the duty of insurers to demonstrate good faith.

State insurance commissioners' offices field complaints regarding insurance contracts and claims handling through the administrative law process. Although there may be little bite behind the individual actions that can be taken in response to these complaints, this often constitutes the simplest, most cost-effective means to get the insurer's attention and to put the file into the hands of a claims manager specifically tasked with fielding and resolving these issues. Insurance regulation, including the Unfair Settlement Claims Practices Model, allows insurance commissioners to investigate insurers who appear to demonstrate a pattern of regulatory violation and to levy fines. Therefore, although an individual complaint may not impact an insurer to any great extent, the cumulative threat of regulatory violation and fines does put the insurer on notice. Failing resolution through the administrative process, the insured's right to sue for bad faith remains intact.

\section{Attorney Measures to Mitigate Cherry-Picking}

The aware patient/plaintiff advocate versed in the insurance industry's "cost containment" practices can frequently shortcircuit the insurer's attempt to manipulate the examiner's opinions. The plaintiff's attorney can request that the insurer provide a complete copy of or, at a minimum, an itemization of records provided to the examiner. The patient or advocate can provide the complete records to the examiner directly. Though doing so requires more effort, the advocate can even provide a summary of the records highlighting those that the insurer is likely to exclude. Should the insurance examiner choose not to review the attorney's record, this provides the advocate additional material with which to challenge the findings and impeach the examiner at deposition.

It should be noted that a claims manager's decision to withhold records from an examining physician is a shortsighted strategy that places a well-intentioned examiner in harm's way. The claims manager's purpose in withholding records would appear to be to avoid the examiner's full knowledge of facts pertinent to the claimant's condition. One can assume that if the records were not seen as detrimental to the insurer's position, they would not be withheld. The examiner who renders an opinion based upon incomplete information is subject to having the omitted records brought to his or her attention during a deposition. Caught unaware, the deponent's opinion is potentially subject to attack while under oath and unprepared.

\section{Case Study}

In certain cases, claimants may not enjoy the benefit of legal representation, or their attorneys may not be sufficiently aggressive in their efforts to protect their rights. Following is a case study from the first author's (MS) clinical practice describing his efforts to protect a patient from a claims manager's efforts to cherry-pick records provided to an IME psychiatrist, with this intervention aimed at sparing the patient from undue stress.

Ron is a 60-year-old quality assurance specialist with a large aeronautics company with a distinguished and lengthy work history. In the normal course of his work, he was struck in the head by a steel beam, subsequent to which he experienced neck pain and headache as well as problems with concentration, memory, and anxiety. He initially sought treatment from his primary care provider, who advised him to open a workers' compensation claim, sensing that he would require considerable rehabilitative treatment. The company for which Ron worked was self-insured, with a 3rd-party administrator in charge of workers' compensation. Initially, the claimant received a very brief course of physical therapy for his pain condition, which reportedly was not helpful. His claims manager then sent him for neurological and neuropsychological IMEs. The claimant eventually sought legal representation and was referred to the first author (MS) for a psychological evaluation. In reading the neuropsychological IME, numerous "errors" were identified and were included in the psychological evaluation report - through which Ron was diagnosed as suffering from a Pain Condition Associated with Both Psychological Factors and a General Medical Condition as well as with an Adjustment Disorder with Mixed Anxiety and Depressed Mood. These diagnoses were directly attributed to his accident-related chronic pain. Although the claims manager initially rejected this claim of a psychological injury, the rejection was appealed to the State Board of Workers' Compensation, which immediately found in the claimant's favor. However, unfortunately, the physical claim was not appealed. Ron spent the following 3 months receiving behavioral medicine counseling, which focused on the management of his chronic pain and its emotional sequelae. The claimant was then notified that he was mandated to attend a psychiatric IME. The treating psychologist sensed a high likelihood of cherry-picking based on past experience, and accordingly chose to contact the IME psychiatrist and asked whether he had received the psychological evaluation that had been provided to the patient several months earlier. When he was told that the psychiatrist had not received the psychological evaluation report, the psychologist obtained a waiver of 
confidentiality from the claimant and then sent the psychiatrist the psychological evaluation report. The treating psychologist felt compelled to intervene in this manner due to the fact that the patient's depression had reached suicidal levels, and his overall resources were limited. The IME was performed, and the psychiatrist found in favor of the claimant and the treating psychologist, recommending continued psychological therapy.

While some have argued against rehabilitation specialist advocacy for individuals with chronic pain as resulting in the potential crossing of ethical boundaries (Sullivan and Main, 2007), others have disagreed with such a perspective (Kornblau and Burkhardt, 2012). In this particular case, the psychologist's failure to provide much-needed advocacy in this case would have likely resulted in successful "cherry-picking" on the part of the claim manager in an effort to create further bias in the psychiatric IME. Had the claims manager's efforts to create this bias been successful, this would have had potentially extremely deleterious results for the vulnerable claimant. Therefore, the psychologist felt that he had a fiduciary obligation to his patient to promote his welfare and minimize potential harm.

Interestingly, the American Psychological Association (APA) Ethical Principles of Psychologists and Code of Conduct (APA, 2010) can be interpreted to indicate that psychologists are actually enjoined to do whatever is ethically necessary, provided that it is legal, to protect the rights of patients. For example, principle A of the General Principles states "... psychologists seek to safeguard the welfare and rights of those with whom they interact professionally..." In the case of Ron, his welfare and rights were clearly at risk of being compromised by a claims manager. Furthermore, principle D of the General Principles states, "Psychologists recognize that fairness and justice entitle all persons to access to and benefit from the contributions of psychology and to equal quality in the processes, procedures, and services being conducted by psychologists." Without the first author's intervention, the IME psychiatrist would have been more likely to have found in the insurer's favor, and the resulting mandate to discontinue treatment would have potentially resulted in Ron being deprived of access to much-needed psychological treatment. Finally, principle E notes, "Psychologists are aware that special safeguards may be necessary to protect the rights and welfare of persons or communities whose vulnerabilities impair autonomous decision making." The patient in this case was clearly quite vulnerable and certainly lacked a sufficient understanding of the IME process to have intervened on his own to ensure that the IME psychiatrist would receive all relevant records, not just those cherry-picked by the claims manager. Accordingly, the psychologist acted in a manner to protect the vulnerable patient's autonomy to choose the treatment that he received, as opposed to allowing the behavior of a claims manager who was unqualified to do so to make the decision for him.

\section{Summary and Conclusions}

The IME process, while clearly necessary, unfortunately becomes flawed when claims managers engage in cherrypicking of records. This practice puts a patient at risk, as decisions made by IME providers based on incomplete information may potentially result in termination of treatmentwhich can have negative psychological as well as physical repercussions. It is important to note, however, that cherrypicking medical records provided to IME physicians is likely an exception rather than the rule. Although rules are in place in many jurisdictions that prohibit cherry-picking, these rules are at times ignored by insurers in order to gain an unfair advantage in their efforts to cost-contain without consideration for an injured patient's well-being. Theoretically, plaintiff's attorneys could potentially cherry-pick records that they are requested to provide, although a review of the literature fails to produce incidence of such behavior. This, however, certainly does not suggest that cherry-picking records by plaintiff's attorneys does not occur or that it is not every bit as inappropriate as is such behavior perpetrated by claims managers or defense attorneys.

Although cherry-picking records provided to IME examiners constitutes bad faith, prohibitive costs have prevented the writing of specific case law to address this inappropriate behavior up to this point. However, filing formal complaints with state insurance commissions in regard to such behavior can serve to level the playing field through the administrative law process. Additionally, the diligent plaintiff's attorney can take measures to mitigate the impact of cherry-picking prophylactically. At times, psychologists serving as advocates, and functioning within the parameters of all appropriate professional guidelines and ethical codes, can also take preemptive measures to ensure that an IME provider is able to have access to all of the relevant records prior to conducting an examination. Although this type of advocacy may be considered controversial, it is not provided that it comports with extant professional guidelines and codes in a system that is not necessarily always just. Accordingly, the practice of cherry-picking IME records may at times justify such supererogatory measures.

\section{References}

American Medical Association. (2005). Standards for independent medical examinations. Available at: http://www.aimehi.com/PDFs/ IME $\% 20$ standards $\% 20$ for $\% 20$ AIMEHI $\% 20$ web $\% 20$ site.pdf. Accessed 1 December 2013.

American Psychological Association. (2010). Ethical principles of psychologists and code of conduct including 2010 amendments. Available at: http://www.apa.org/ethics/code/index.aspx. Accessed 26 January 26, 2014. 
Appleby, K. S., \& Tarver, J. (2006). Medical records review (4th ed.). New York: Aspen Publishers.

Baer, M. A. (2005). Opinion piece: is an independent medical evaluation independent? Forensic Examiner, 14, 33.

Benner, D. E. (2007). Ethical issues of chronic pain from a patient's perspective. In M. E. Schatman (Ed.), Ethical issues in chronic pain management (pp. 15-32). New York: Informa Healthcare.

Black, H. C., \& Nolan, J. R. (1999). Black's law dictionary: definitions of the terms and phrases of American and English jurisprudence ancient and modern; [with pronunciations] (7th ed.). St. Paul: West Publ.

Brown v. Superior Court (1949), 34 Cal.2d 559, 564 [212 P.2d 878].

Bush, S. S., \& Heilbronner, R. L. (2012). The neuropsychological IME. In S. S. Bush \& G. L. Iverson (Eds.), Neuropsychological assessment of work-related injuries (pp. 280-302). New York: Guilford Press.

Colorado Department of Labor \& Employment. (2013). Rule 11 Division Independent Medical Examination. Available at: http:// www.colorado.gov/cs/Satellite? $\mathrm{c}=$ Page\& childpagename $=\mathrm{CDLE}-$ WorkComp $\% 2$ FCDLELayout\&cid $=1251567882380 \&$ pagename $=$ CDLEWrapper\#Rule 11-6. Accessed 1 December 2013.

Comunale v. Traders \& General Ins. Co. (1958), 50 Cal.2d 654.

Dersh, J., Polatin, P. B., Leeman, G., \& Gatchel, R. J. (2004). The management of secondary gain and loss in medicolegal settings: strengths and weaknesses. Journal of Occupational Rehabilitation, 14, 267-279.

Eisendrath, S. J., Rand, D. C., \& Feldman, M. D. (1996). Factitious disorders and litigation. In M. D. Feldman \& S. J. Eisendrath (Eds.), The spectrum of factitious disorders (pp. 65-82). Washington: American Psychiatric Association Press.

Gaughwin, P. C. (2004). Beyond the noise and smoke: some challenges for mental health professionals entering the forensic arena. Psychiatry, Psychology and Law, 11, 44-49.

Green, S. (2011). The medicalization of episodic regional backache. Ethics in Biology, Engineering and Medicine, 2, 237-251.

Greve, K. W., Ord, J. S., Bianchini, K. J., \& Curtis, K. L. (2007). Prevalence of malingering in patients with chronic pain referred for psychologic evaluation in a medico-legal context. Archives of Physical Medicine and Rehabilitation, 90, 1117-1126.

Gruenberg v. Aetna Ins. Co. (1973), 9 Cal.3d 566, 575.

Hilker v. Western Automobile Ins. Co. (1930), 204 Wis. 1 [231 N.W. 257, 258] (aff'd on rehg., 204 Wis. 1 [235 N.W. 413].

Howard, K. J., Kishino, N. D., Johnston, V. J., Worzer, W. E., \& Gatchel, R. J. (2010). Malingering and pain: Is this a major problem in the medicolegal setting? Psychological Injury and Law, 3, 203-211.

Kornblau, B. L., \& Burkhardt, A. (2012). Ethics in rehabilitation: a clinical perspective (2nd ed.). Thorofare: SLACK Incorporated.

Kulich, R. J., \& Baker, W. K. (1997). Psychologic evaluation in the management of chronic pain and disability. Current Pain and Headache Reports, 1, 116-125.

Ky, P., Hameed, H., \& Christo, P. J. (2009). Independent medical examinations: facts and fallacies. Pain Physician, 12, 811-818.

Law Society of New Brunswick, College of Physicians and Surgeons of New Brunswick, New Brunswick Medical Society, Canadian Bar
Association-New Brunswick Branch. (2002). Interactions Between Lawyers and Physicians in Litigation. Available at: http:// www.lawsociety-barreau.nb.ca/assets/documents/ INTERACTION\%20Lawyers\%20Physicians.\%20English.pdf. Accessed 1 December 2013.

Lax, M. B., Manetti, F. A., \& Klein, R. A. (2004). Medical evaluation of work-related illness: Evaluations by a treating occupational medicine specialist and by independent medical examiners compared. International Journal of Occupational and Environmental Health, 10, 1-12.

Martelli, M. F., Zasler, N. D., \& Grayon, R. (1999). Ethical considerations in impairment and disability evaluations following acquired brain injury. In V. R. May \& M. F. Martelli (Eds.), Guide to functional capacity evaluation with impairment rating applications (pp. 204270). Richmond: NADEP Publications.

Maryland Workers' Compensation. (2013). Workers' Compensation Medical Records. Available at: http://www.mdcomplaw.com/info/ medical/workers-compensation-medical-records/. Accessed 30 December 2013.

National Association of Insurance Commissioners, Model Regulation Service - July 1997, Model 902 Available at: http://www.naic.org/ store/free/MDL-902.pdf. Accessed 19 January 2014.

Ochoa, J. L., \& Verdugo, R. J. (2010). Neuropathic pain syndrome displayed by malingerers. Journal of Neuropsychiatry and Clinical Neuroscience, 22, 278-286.

Oregon Department of Consumer and Business Services. Guide to Providing Independent Medical Exams. (2011). Available at: http://www.cbs.state.or.us/wcd/communications/publications/4913. pdf. Accessed 30 December 2013.

Schatman, M. E. (2011). The role of the health insurance industry in perpetuating suboptimal pain management. Pain Medicine, $12,415-426$.

Schatman, M. E. (2012). Workers compensation and its potential for perpetuation of disability. In R. J. Gatchel \& I. Z. Schultz (Eds.), Handbook of occupational health and wellness (pp. 341-361). New York: Springer.

Schatman, M. E., \& Sullivan, J. (2010). Whither suffering? The potential impact of tort reform on the emotional and existential healing of traumatically injured chronic pain patients. Psychological Injury and Law, 3, 182-202.

Schofferman J. (2007). Opinions and testimony of expert witnesses and independent medical evaluators. Pain Medicine, 8, 376-82.

Stempel, J. W. (2009). The "other" intermediaries: the increasingly anachronistic immunity of managing general agents and independent claims adjusters. Connecticut Insurance Law Journal, $15,599-721$.

Sullivan, M. D., \& Loeser, J. D. (1992). The diagnosis of disability: treating and rating disability in a pain clinic. Archives of Internal Medicine, 152, 1829-1835.

Sullivan, M. J. L., \& Main, C. (2007). Service, advocacy and adjudication: balancing the ethical challenges of multiple stakeholder agendas in the rehabilitation of chronic pain. Disability and Rehabilitation, 29, 1596-1603. 